\title{
DESIGN FOR SUSTAINABLE BEHAVIOUR IN PRODUCT/SERVICE SYSTEMS - A SYSTEMATIC REVIEW
}

\author{
Gustafsson, Karoline Fogh; \\ Harild, Sara Amdi; \\ Pigosso, Daniela C. A. \\ Technical University of Denmark
}

\begin{abstract}
Product-service/systems (PSS) have been projected to be a potential solution to address overconsumption and to enable an enhanced sustainability performance. However, PSS do not always live up to their potential benefits, due to unintended changes in consumer behaviour. This study aims at investigating existing methods and tools to develop sustainable behaviour within PSS, alongside potential barriers and success factors. Based on a systematic literature review, a total of 46 methods to achieve sustainable behaviour were collected and analysed, and further discussed on the basis of the identified success factors and barriers.
\end{abstract}

Keywords: Sustainability, Product-Service Systems (PSS), Circular economy, Design for Sustainable Behaviour

\section{Contact:}

Pigosso, Daniela

Technical University of Denmark

Department of Mechanical Engineering

Denmark

danpi@dtu.dk 


\section{INTRODUCTION}

Climate change remains one of the biggest threats to our world's societies, and we need to drastically innovate to come up with solutions to target our emissions and overconsumption. Product/servicesystems (PSS) have formerly been highlighted as a promising part of the solution as it: allows more users per produced product, is projected to take better advantage of products, and even prolong their lifespan, thereby reducing their environmental impact (Manzini \& Vezzoli, 2002). This is, however, not always the case despite their ambitious intentions (Kjaer et al., 2019). As the ownership of products in PSS is transferred or shared between users and suppliers, the products are treated differently by the users. One example is the electric scooters that can be rented by the minute in several European metropolises. They only operate for 29 days before being scrapped (Lindholdt, 2019), partially caused by users not handling the scooters correctly. Similarly, the baby stroller manufacturer, Bugaboo, found that by offering their products as a PSS, one third of all strollers were highly damaged and needed refurbishment after only one use-cycle (Sumter, Bakker, \& Balkenende, 2018). This conflicted with the expected durability of Bugaboo, which suggests a change in user behaviour in a PSS compared to purchased products. Thereby the behaviour of the users within these systems jeopardises the environmental impact of PSS, and their potential is overshadowed by negligent consumer behaviour.

This study was initiated to investigate potential mitigations or design choices that could make users treat PSS more sustainably and thereby improve their environmental performance. The ultimate aim is to support designers to create or redesign PSS that can trigger a more sustainable behaviour; support that is sought developed through design methods as the majority of environmental impacts are determined during conceptualisation in the design phase (McAloone and Bey, 2009; Pigosso and McAloone, 2015; Blomsma et al., 2018). To develop meaningful support while standing on the shoulders of giants, it is crucial to know the state-of-the-art methods targeting unsustainable use of products, and to what extent and how successfully these are applied in a PSS context. This was done through a systematic review with the following two objectives: (1) Systematise methods and tools for the development of product/servicesystems based on "design for sustainable behaviour" (DfSB); (2) Identify barriers and success factors in design for sustainable behaviour within product/service-systems.

\section{BACKGROUND: DESIGN FOR SUSTAINABLE BEHAVIOUR}

Design for Sustainable Behaviour is a design approach that aims at improving the sustainability performance of products, services, and systems during their use phase (Selvefors \& Renström, 2018). DfSB is an ever-expanding field that continues to gain interest due to its increased relevance, both in user-oriented design (correct utilization of products) and later sustainable design (sustainable use of products). Within the field, some of the most well know frameworks or methods are presented here, as they form the foundation of the field of DfSB.

Lilley (2009) applies three behaviour intervention strategies in the design: eco-feedback to guide change (i.e. tangible signs as reminders to inform users of resource use), behaviour steering to maintain change (i.e. encourage users to behave sustainably based on embedded affordances and constraints), and persuasive technology to ensure change (i.e. methods to influence what people think or do). The strategies are placed relative to power in decision-making, whether the user or the product has the power to change the behaviour. Zachrisson \& Boks (2010) connect the effectiveness of behaviour intervention strategies to the user's attitude to help designers decide which behaviour intervention strategy to apply. Informative behaviour intervention strategies require a willingness to change behaviour, thus, a positive attitude towards the intended behaviour.

In 2009, Lockton, Harrison, and Stanton present their proposed framework Design with Intent. This design tool is created for designers to be able to influence the behaviour of users in a general manner (including and going beyond sustainable behaviour). The goal of the tool is to redesign a behaviour towards a particular desired behaviour through the use of six "lenses": (1) error-proofing lens (deviations from target behaviour are treated as "errors"). (2) persuasive lens (use systems with interfaces to persuade users with information). (3) visual lens (use forms, smells, sounds, textures, etc. to influence users' behaviour). (4) security lens (use countermeasures to deter and/or prevent undesired behaviours). (5) cognitive lens (influence users' behaviour by understanding how they make decisions). (6) architectural lens (use the structure of systems to influence users' behaviour). The lenses are based on different behaviour strategies that help the designer approach a solution from 
different perspectives. The lenses can be used loosely as an inspiration for concept development or in a more structured way by breaking target behaviours down to interactions in a prescription mode which serves as a prescribed design process in the development phase.

Tromp, Hekkert, \& Verbeek (2011) describe a framework for socially responsible behaviour that explains the relationship between the product, human behaviour, and its implications. It consists of 11 behaviour strategies split into four categories: decisive, coercive, seductive, and persuasive influences. These 11 strategies intend to inspire the generation of ideas when designing for certain behaviour. It is argued that a design may be categorised differently according to the specific user utilizing the design. Tromp et al. (2011) argue that there is a need to investigate the social implications that come with the framework presented by Lockton et al. in 2009, which this framework is a response to. Once selecting a strategy, the designer should take into account whether there are conflicts between individual and collective concerns, which should then inform the choice of strategy.

Selvefors \& Renström (2018) present a holistic approach of how to create sustainable behaviour within different layers of design, ranging from what activity to enable users to perform to how different functions are communicated to the user. Selvefors \& Renström mention that a variety of different behaviour strategies can be used to affect behaviour within different layers of design, which they suggest, can be sorted into five categories: Enlighten, spur, steer, force and match (see Figure 5). Looking at the early research and tools within DfSB, this division of behaviour strategies shows to be applicable as well. E.g., Lilley's Eco-feedback (2009) belongs to enlighten, and Lockton et al.'s architectural lens (2009) is a steering strategy, as it is directing the user to make the sustainable choice. A common trait among these DfSB frameworks is that not one of them is directly linked to the development nor redesign of PSS. Lockton et al. (2009) mention that the framework is especially relevant for systems "where users' behaviour is important to its operation..." which would include PSS, yet this may just as well refer to products that operate with high-energy consumption. Therefore, a broader search of what exists within the field is necessary.

\section{RESEARCH METHODOLOGY}

The main objective of this study is to systematise methods and tools for the development of PSS based on DfSB. Furthermore, to identify barriers and success factors in the same field of research as the stepping-stone to evaluate methods and tools for future work. A systematic review was conducted to reach the objectives. The review protocol is structured based on PRISMA-P with the inclusion of elements from Biolchini et al. (2007).

Studies were collected through Scopus based on the following search string:

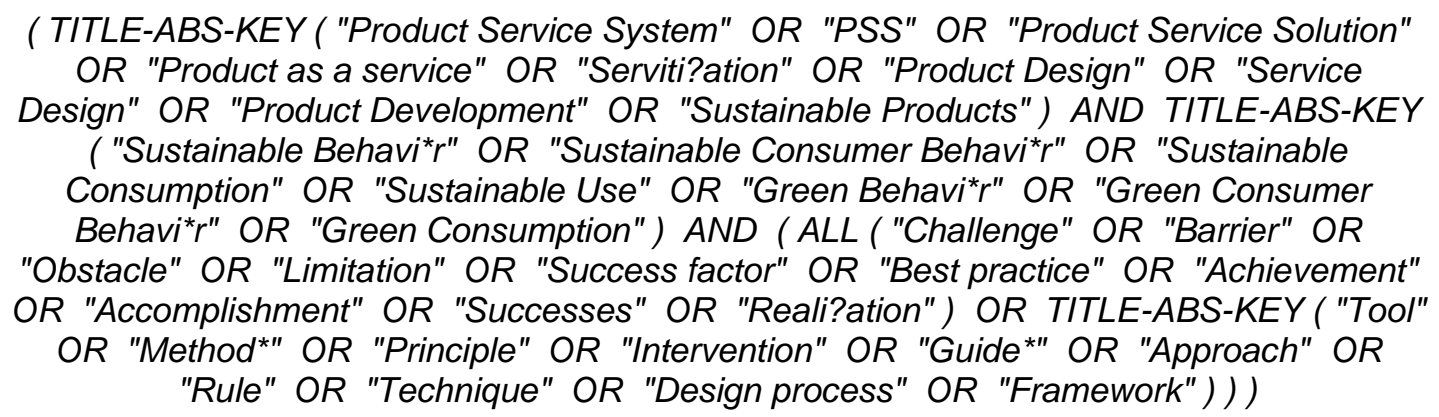

The relevant studies were selected according to the following criteria, reflecting the objectives of the study: (1) studies must describe observed barriers in designing for sustainable consumer behaviour; (2) studies must describe success factors in designing for sustainable consumer behaviour; (3) studies must include methods and/or tools targeted towards designing for sustainable consumer behaviour. The initial set of studies were selected with an abstract, keyword, and title only search; barriers and success factors were sought for in full articles. An evaluation of the systematic review execution was performed, investigating potential limitations of web search engines utilised in the study.

The search returned 263 unique studies that were first screened by the abstract according to the three criteria, which resulted in 168 articles left for eligibility. These were sorted by reading the full text of the study. The execution of the systematic review included 51 studies, in total, for further analysis. The 51, initially 53, was re-iterated to clean the data. 


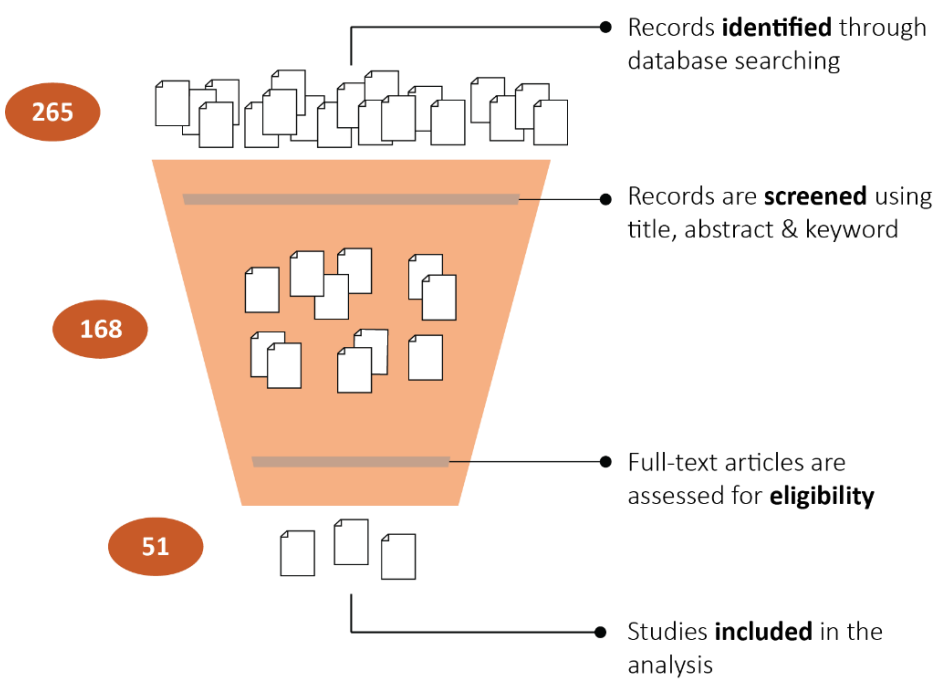

Figure 1. Systematic review process and result of screening and eligibility

The 51 studies were analysed by identifying the following parameters:

- General information: type of system (product, service, PSS, system); and type of product (consumables, mobility, energy, etc.)

- Methods and tools: type (framework, method, tool, approach, business model, guideline, initiative, model, procedure, process, strategy, toolbox, toolkit, typology); name; description; goal; design phase (discover, define, develop, deliver (Design Council, 2019)) and performance

- $\quad$ Success factors and barriers

- Behavioural intervention strategies

Methods and tools were also denoted as a framework, a process, etc., as the terminology used is based on that stated in the study, and thus, not critically assessed whether the use of definitions has been used similarly. Therefore, the use of the word method will hereinafter entail all the terms stated previously. A success factor is identified as an entity necessary to reach a successful outcome of the method. A barrier is closely related to success factors. However, a barrier describes an entity that prevents a successful outcome of a method. The parameters were further analysed and split into groups. The groups were defined from a bottom-up approach. Behaviour principles were grouped in accordance with Selvefors \& Renström (2018), as these categories could grasp the wide variety of principles found, see Table 1.

Table 1. Grouping descriptions for behaviour intervention strategies adopted by (Selvefors and Renström, 2018) for enlighten, force, spur, steer and match

$\begin{array}{lll}\text { Strategy group } & \text { Types of behaviour principles } & \text { Example(s) }\end{array}$

\begin{tabular}{|c|c|c|}
\hline Enlighten & $\begin{array}{l}\text { Motivate users by increasing their knowledge, } \\
\text { which also include information given to the users } \\
\text { about the environmental effects of their behaviour }\end{array}$ & $\begin{array}{l}\text { Eco-feedback, eco- } \\
\text { information, and eco-labels }\end{array}$ \\
\hline Spur & $\begin{array}{l}\text { Encourage users to reduce the environmental } \\
\text { effects of their behaviour, also by adding focus on } \\
\text { other gains besides environmental }\end{array}$ & $\begin{array}{l}\text { Self-monitoring, } \\
\text { competition, eco-spur }\end{array}$ \\
\hline Steer & $\begin{array}{l}\text { Make the most sustainable behaviour an obvious } \\
\text { choice for the user through product and service } \\
\text { design }\end{array}$ & $\begin{array}{l}\text { Scripting, persuasive } \\
\text { technologies, emotional } \\
\text { appeal, eco-steer }\end{array}$ \\
\hline Force & $\begin{array}{l}\text { Make it impossible not to choose the most } \\
\text { sustainable behaviour for the user }\end{array}$ & $\begin{array}{l}\text { Forced functionality, clever } \\
\text { design, eco-technology }\end{array}$ \\
\hline Match & $\begin{array}{l}\text { Adapt products and services to existing user } \\
\text { behaviour, which is designed to reduce } \\
\text { environmental effects of their behaviour }\end{array}$ & $\begin{array}{l}\text { Functionality matching, } \\
\text { functionality adapting }\end{array}$ \\
\hline
\end{tabular}




\section{RESULTS}

The studies included in the analysis started being published in 2002, and the number of studies has since steadily grown each year, as seen in Figure 2. The findings indicate that research concerning DfSB is increasingly becoming of interest. However, with a total amount of 51 articles included in the analysis, the field is still quite new and premature. The research has also developed in different directions over the years. Some of the first studies published focus on modular upgradability (Briceno \& Stagl, 2006) and user-centred design (Wever, van Kuijk, \& Boks, 2008) until the integration of psychology (Gulden et al., 2010; Cheng et al., 2014).

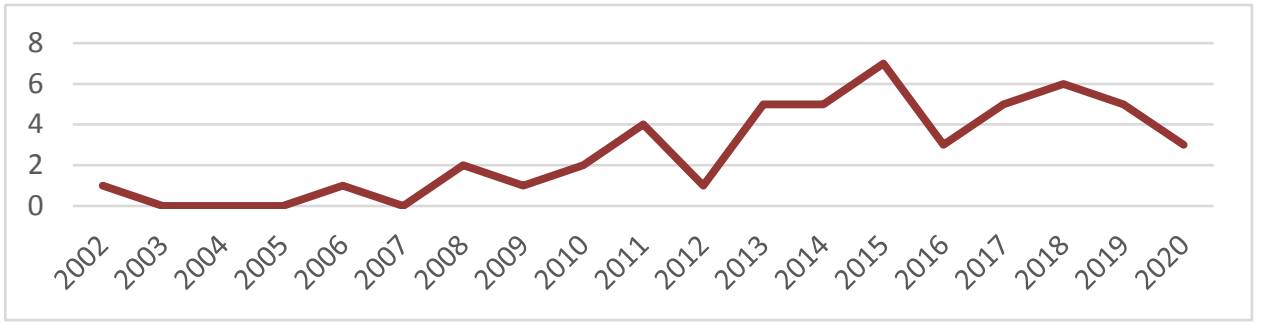

Figure 2. Number of articles published per year included in the analysis

In the 51 studies, a total of 45 methods are presented. An overview of the methods is found in Figure 3 , showing the distribution of methods focusing on product design (28), product or service design (5), service design (1), circular economy design (5), PSS design (5), and system design (1). Thus, the DfSB methods are mainly thought to be applied to products.

\subsection{Methods and tools for DfSB}

The methods have been analysed according to which design phase(s) (discover, define, develop, deliver) they are targeted towards, as the double diamond framework (Design Council, 2019) is often used to develop the value proposition of PSS (Rozenfeld et al., 2019; Chunmao and Lei, 2020; Fernandes et al., 2020). 18 methods targeted discover, 19 targeted define, 41 targeted develop and 11 targeted deliver. This shows a clear focus on the development of behaviour strategies and interventions. As the focus of the study is founded on behaviour interventions and change, the studies included will naturally be focusing on redesigning to avoid unsustainable behaviours since a prerequisite for change is an existing behaviour. Thereby the design process is initiated with an existing problem, which may be the reason for a majority of methods focusing on the solution space rather than the problem space. Only six methods target all four design phases, indicating a gap of holistic DfSB approaches grasping the full design process. The type of product suggested or applied in the method has been indicated with colour in Figure 3. This figure shows that 14 studies target different consumables, while 15 target consumer electronics. Including products such as a lamp, washing machine, interfaces in building, mobility, and energy, a total of 21 articles target behaviours to reduce energy usage. This may be caused by the fact that high energy usage of products can be directly related to the behaviour users have around a product in its use phase, which clearly has an environmental impact. The complete list of the identified methods, with their respective codes, descriptions, and references, can be found at (https://cutt.ly/ihIR7fW).

\subsection{Behavioural intervention strategies}

To gain an understanding of which behavioural intervention strategies were applied within the DfSB field, all strategies were listed for each method included in the analysis (Table 2). Enlighten and steer are the most applied strategies with 56 and 58 occurrences, respectively.

Table 2: Behavioural strategies divided into system types based on recurrence

Product

Product, service

Circular economy

PSS

Service

Total

\begin{tabular}{llllll} 
Enlighten & Spur & Steer & Force & Match & Total \\
\hline 51 & 29 & 47 & 12 & 3 & 142 \\
3 & 2 & 10 & 3 & 0 & 18 \\
0 & 0 & 0 & 0 & 0 & 0 \\
2 & 0 & 1 & 0 & 0 & 3 \\
0 & 3 & 0 & 0 & 0 & 3 \\
56 & 34 & 58 & 15 & 3 & 166
\end{tabular}




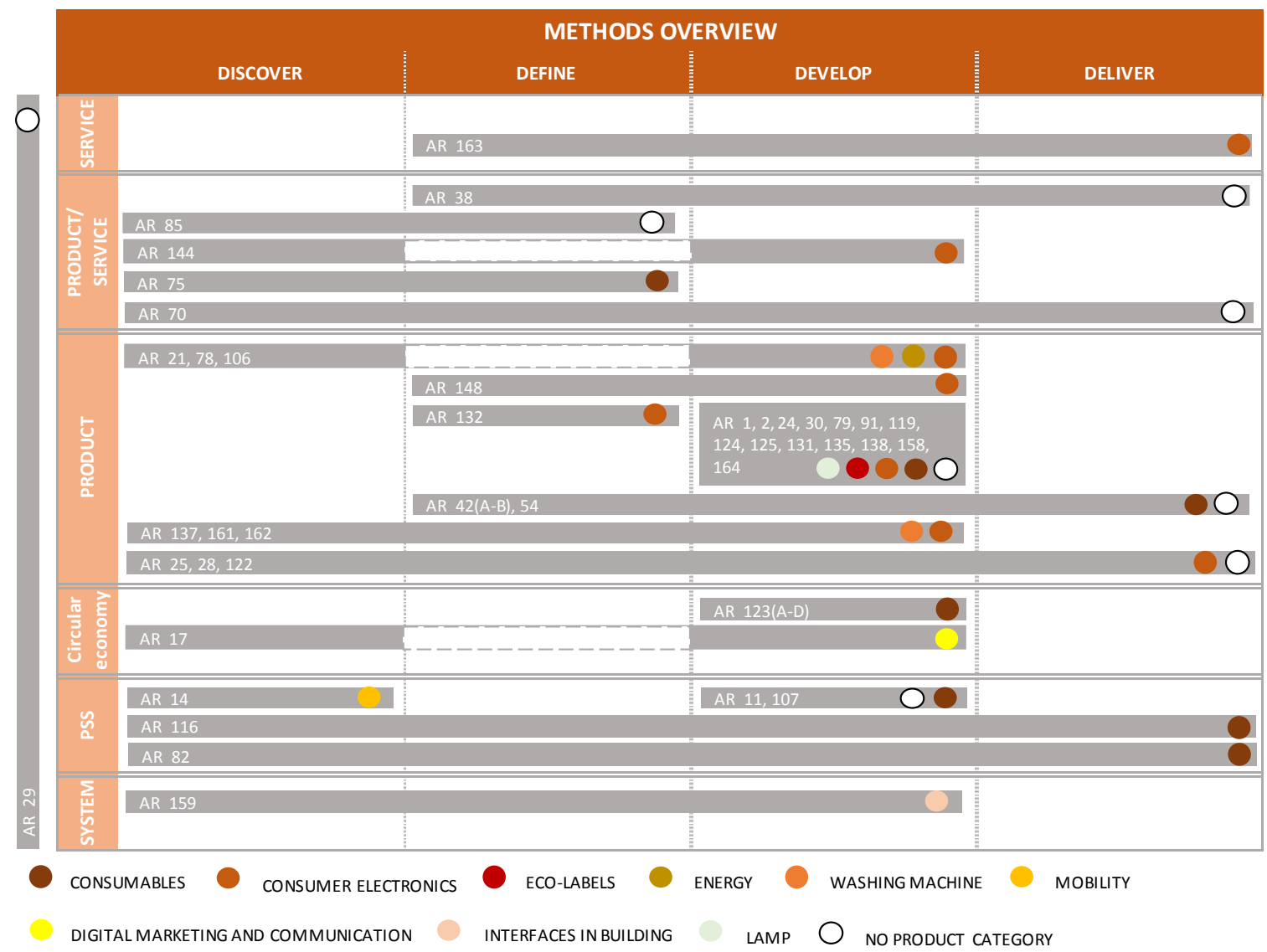

Figure 3. Overview of DfSB methods. Colours indicate applicable product type.

Spur strategies are also frequently applied, with 34 occurrences, especially within consumer electronics and energy-related products, with 28 occurrences as seen in Table 3 . This table also shows that a vast majority of the behaviour strategies occur in articles focusing on consumer electronics (99), despite an even distribution between articles regarding consumer electronics (15) and consumables (14). This may indicate that behaviour strategies mostly target consumer electronics as they may be easier or cheaper to implement in consumer electronics compared to other consumables.

Table 3: Behavioural strategies divided into product types based on recurrence

\begin{tabular}{lllllll} 
& Enlighten & Spur & Steer & Force & Match & Total \\
\cline { 2 - 7 } Consumer electronics & 40 & 21 & 28 & 9 & 1 & 99 \\
Consumables & 13 & 5 & 16 & 3 & 1 & 38 \\
Energy & 2 & 7 & 2 & 1 & 1 & 13 \\
Total & 56 & 33 & 46 & 13 & 3 & 150
\end{tabular}

A total of 166 strategies are mentioned across the 45 methods. Generally, enlighten, spur, and steer categories have the highest recurrence, which can be due to their low-cost high-gain condition as compared to force mechanisms, which may risk scaring away customers, and match strategies that can be resource-intensive to incorporate.

\subsection{Barriers and success factors}

In total, 31 barriers and 18 success factors were identified within the 51 studies. They were grouped based on the description (see Appendix A) and whether they were general or specific to the method as seen in Figure 4. 


\begin{tabular}{|c|c|c|c|}
\hline \multicolumn{4}{|c|}{ BARRIER \& SUCCESS FACTOR GROUPS } \\
\hline & & GENERAL & METHOD-SPECIFIC \\
\hline \multirow{10}{*}{$\frac{u}{\frac{a}{u}}$} & Differences in large consumer groups & AR 106 & 160 \\
\hline & Knowledge gap & AR $26(5), 78(3), 103,106$ & 125,158 \\
\hline & Limitation & & AR $1(5), 160(2)$ \\
\hline & Oversimplification of users & & AR 85 \\
\hline & Practices develop over time & AR 106 & \\
\hline & Rebound effects & & AR $160(2)$ \\
\hline & Specialist knowledge & & AR 4,122 \\
\hline & Sustaining behaviour change & AR 72 & 160 \\
\hline & Time and resources & & AR 4 \\
\hline & Turning theory into practise & AR 4 & \\
\hline \multirow{8}{*}{ 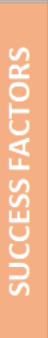 } & Accompagnied by other theory & AR 55 & 85,122 \\
\hline & Innovativeness & & AR 11 \\
\hline & Need for user inclusion & AR 29,158 & 138 \\
\hline & Ressource intensive & AR $72(2)$ & 158 \\
\hline & Target moments of transition & AR 72 & \\
\hline & The amount of trust in the system & & AR 11 \\
\hline & Users' understanding & AR 48 & \\
\hline & User satisfaction & AR $76(2)$ & $11(2), 138$ \\
\hline
\end{tabular}

Figure 4: Barriers and success factors grouped across articles. Parenthesis indicates the number of success factors or barriers mentioned in the study within a certain group.

In total, 14 were general barriers to achieving sustainable behaviour, and 17 were method-specific barriers. Knowledge gap is by far the most prominent barrier (12) indicating the general prematurity of the field. Regarding success factors, nine were method-specific, while the remaining nine were general in terms of the success of the behavioural interventions. User satisfaction is the type of success factor mentioned most in the study (5), underlining the importance of satisfied users to gain successful behaviour change, followed by the need for user inclusion (3) (highly related to user satisfaction), and accompanied by other theory (3).

\section{DISCUSSION}

The analysis of the 51 eligible studies resulted in 45 methods, 31 barriers, and 18 success factors. However, only 11 studies addressed PSS, and just six of these targeted PSS directly. These six methods indicated all different types of limitations ranging from the lack of testing the methods on real-life cases, the limited amount of products/ PSS they were tested on, to the lack of thorough prescriptions of how to apply one or multiple steps into a design process. Additionally, none of these six methods targeted to change the unsustainable behaviours stemming from the transformed ownership embedded in the PSS. All of which suggests that the field is unexplored and needs further development.

Interestingly, three studies suggested that DfSB methods could be applied to both products and product/service-systems. The studies did, however, not touch upon the fundamental differences between the two in terms of the relationship between user and provider as well as the motivation behind behaviours. The presence of these differences is supported by Catulli et al. (2017), who argue that ownership of a product is culturally important for the user's identity and social status and that PSS cannot fulfil these needs. Thus, PSS cannot obtain the same attractiveness even with additional functional offerings as ownership of products. We argue that the differences stretch beyond the purchase decision and into the use phase, where the same social attachments to the product will lack in a PSS and result in a changed (and unsustainable) behaviour.

Common for most methods in the analysis is the process of selecting the most effective and relevant behavioural intervention strategies. This is a complex task as it depends on the type of product (Chamberlin \& Boks, 2018), the attitude of the user (Zachrisson \& Boks, 2010), and the cultural context (Santamaria et al., 2016). This indicates that there are several context-specific factors critical to achieving sustainable behaviour through the methods. The question is whether the conditions of PSS should be considered as a variation of such factors, thereby complicating the choice of 
intervention strategies to be used in a PSS context (de Pádua Pieroni et al., 2018). This can be an explanation for the prematurity of the methods within the field.

As the complexity of selecting intervention strategies is rather high, they are either tackled by an extensive amount of knowledge, as in the case of Chamberlin \& Boks (2018). Shih et al. (2017) suggest a data-driven approach to address the complexity, yet this is a highly resource-intensive approach. Thereby this complexity of the field somewhat serves as a high entry-barrier that can only be overcome by extensive knowledge or resources to successfully utilise and apply DfSB. Shih et al. (2017) suggest a data-driven approach to combat the complexity, yet this is a highly resource-intensive approach. Thereby this complexity of the field serves as a high entry-barrier to successfully utilise and apply DfSB.

In total, 21 out of the 51 studies included in the analysis focused on the design of energy-consuming products such as consumer electronics, interfaces in buildings, washing machines, etc. This distribution suggests that either the potential of changing energy-consuming behaviours is significant (Liedtke et al., 2015), or it is less resource demanding to incorporate behavioural interventions for these products. As digitalisation has also become very popular over the years, this focus on consumer electronics could also be caused by the trend. However, consumer electronic products are not alone when it comes to being used unsustainably, as seen in the case of Bugaboo. Non-electronic products may just as well be treated unsustainably, yet the relevance for prolonging product lifetime and preserving the products in use remains the same whether products are electronic or not. Therefore, there is a need for an extension of the research, investigating DfSB without the use of intervention strategies focused on electronics.

\section{CONCLUSION}

This research aimed at systematising methods and tools for the development of PSS based on DfSB and to identify barriers and success factors with the long-term objective of supporting designers in creating or redesigning PSS so that users will use them with more sustainable behaviour. In theory, this review contributes by showing a gap in the current research within the field of DfSB targeting PSS. To the knowledge of the authors, this review is the first of its kind, combining an overview of DfSB methods, success factors and barriers in a PSS context. The review found that methods with the potential to achieve sustainable behaviour in PSS do exist, but the limited number of studies combined with the number of success factors and barriers indicate that the methods have yet to be proven. Thus, in practice the review contributes with an overview of categorised methods to guide designers in selecting between existing DfSB methods. In the analysis of the methods, we found a majority of methods having a limited prescribed procedure. Applying the methods to the redesign of a PSS would thus provide essential knowledge for the further development of DfSB in PSS. Thus, further work will include an evaluation of the different methods currently available based on the identified success factors and barriers and applying the method(s) that shows the most potential in the redesign of a PSS. As only few methods grasped an entire design process, a consolidation of methods and tools may be required to support designers with a holistic approach. Further work also includes an investigation of unsustainable behaviour in PSS. As most research within DfSB is focused on product design, exploration of drivers to unsustainable behaviour in PSS is needed to identify behaviour intervention strategies suited to behaviour change in this context, which both includes more elements (product, service, network and infrastructure (Mont, 2004)) to redesign and another ownership compared to traditional consumption of sold products. Additionally, methods could be enriched by looking into behavioural economics principles, as also PSS offer novel business models and ways of delivering value. This research is the first step towards developing a DfSB method applicable to support designers in redesigning PSS to enable more sustainable use of such systems.

\section{APPENDIX: DESCRIPTION OF SUCCESS FACTORS AND BARRIERS}

\begin{tabular}{ll} 
Success group & Description \\
\hline $\begin{array}{l}\text { Accompanied by } \\
\text { other theory }\end{array}$ & $\begin{array}{l}\text { Should be used together with other theory, methods, or models. Both those that } \\
\text { exist, but also those that have yet to be developed }\end{array}$ \\
Innovativeness & Products and PSS should be innovative to attract customers \\
Need for user & Users should be included in the design process, e.g. through surveys, user \\
inclusion & testing or co-creation \\
Resource & Methods are resource-intensive in terms of time, skills, or other support from \\
intensive & surroundings systems, etc.
\end{tabular}


Target moments of transition The amount of trust in the system Users' understanding User satisfaction

The behaviour intervention strategies should target a wider social context, e.g. transitions in life

Customers need to have trust in the system surrounding PSS to reach the sustainable potential

Users need to understand sustainable consumption to perform sustainable behaviour

Sustainable behaviour intervention strategies embedded in products/services should increase user satisfaction, improve life quality and empowerment feeling

\begin{tabular}{|c|c|}
\hline Barrier group & Description \\
\hline $\begin{array}{l}\text { Differences in } \\
\text { large consumer } \\
\text { groups }\end{array}$ & $\begin{array}{l}\text { Methods highlight a barrier concerned by the fact the consumer group is highly } \\
\text { varied and therefore may need different approached }\end{array}$ \\
\hline Knowledge gap & $\begin{array}{l}\text { This type of barrier is described as the field, tool or theory being under- } \\
\text { developed or the need for }\end{array}$ \\
\hline Limitation & $\begin{array}{l}\text { Barriers that describe a condition or principle that seem to limit or hinder } \\
\text { behaviour change }\end{array}$ \\
\hline $\begin{array}{l}\text { Oversimplification } \\
\text { of users }\end{array}$ & $\begin{array}{l}\text { Some methods are limited as there are risks of oversimplification of the types } \\
\text { of users present in the target group }\end{array}$ \\
\hline $\begin{array}{l}\text { Practices develop } \\
\text { over time }\end{array}$ & Barriers that point towards that human behaviour changes over time \\
\hline Rebound effects & $\begin{array}{l}\text { Barriers highlight that some methods or approaches may lead to rebound } \\
\text { effects jeopardising the environmental impact }\end{array}$ \\
\hline $\begin{array}{l}\text { Specialist } \\
\text { knowledge }\end{array}$ & $\begin{array}{l}\text { Barriers evolving around a need for specialist knowledge with the designer to } \\
\text { utilise the method }\end{array}$ \\
\hline $\begin{array}{l}\text { Sustaining } \\
\text { behaviour change }\end{array}$ & $\begin{array}{l}\text { Barriers indicating implications with sustaining a behaviour change over a } \\
\text { longer period of time }\end{array}$ \\
\hline $\begin{array}{l}\text { Time } \quad \text { and } \\
\text { resources }\end{array}$ & Methods being time and resource-intensive \\
\hline $\begin{array}{l}\text { Turning theory } \\
\text { into practice }\end{array}$ & $\begin{array}{l}\text { Barriers regarding the fact that students are taught certain methods or theories, } \\
\text { yet they fail to turn them into practice }\end{array}$ \\
\hline
\end{tabular}

\section{REFERENCES}

Biolchini, J., Mian, P. G., Natali, A. C. C., \& Travassos, G. H. (2005). Systematic Review in Software Engineering. 679(05).

Blomsma, F. et al. (2018) 'Exploring Circular Strategy Combinations - towards Understanding the Role of PSS', Procedia CIRP, 69, pp. 752-757. https://dx.doi.org/10.1016/j.procir.2017.11.129.

Briceno, T., \& Stagl, S. (2006). The role of social processes for sustainable consumption. Journal of Cleaner Production, 14(17), 1541-1551. https://doi.org/10.1016/j.jclepro.2006.01.027

Catulli, M., Cook, M., \& Potter, S. (2017). Product Service Systems Users and Harley Davidson Riders: The Importance of Consumer Identity in the Diffusion of Sustainable Consumption Solutions. Journal of Industrial Ecology, 21(5), 1370-1379. https://doi.org/10.1111/jiec.12518

Chamberlin, L., \& Boks, C. (2018). Marketing approaches for a circular economy: Using design frameworks to interpret online communications. Sustainability (Switzerland), 10(6). https://doi.org/10.3390/su10062070

Cheng, Y.-T., Shih, L.-H., \& Ha, J. (2014). Design framework of household appliance for users' sustainable behaviors. Anthropologist, 17(3), 701-711. https://doi.org/10.1080/09720073.2014.11891484

Chunmao, W. U. and Lei, C. (2020) 'Types and Models of Product-Service System in Design Agencies', Journal of Donghua University, 37(5). Available at: https://www.researchgate.net/profile/ChunmaoWu/publication/347935184_Types_and_M_odels_of_Product-

Service_System_in_Design_Agencies/links/5fe88ac2a6fdccdcb807eec1/Types-and-M-odels-of-ProductService-System-in-Design-Agencies.pdf (Accessed: 20 March 2021).

Daae, J. Z., \& Boks, C. (2014). Dimensions of behaviour change. Journal of Design Research, 12(3), 145-172. https://doi.org/10.1504/JDR.2014.064229

De Medeiros, J. F., Da Rocha, C. G., \& Ribeiro, J. L. D. (2018). Design for sustainable behavior (DfSB): Analysis of existing frameworks of behavior change strategies, experts' assessment and proposal for a decision support diagram. Journal of Cleaner Production, 188, 402-415.

https://doi.org/10.1016/j.jclepro.2018.03.272 
De Pádua Pieroni, M., et al. (2018) 'Enabling circular strategies with different types of product/service-systems', Procedia CIRP, 73, pp. 179-184. doi: https://doi.org/10.1016/j.procir.2018.03.327.

Design Council. (2019). Double Diamond. Retrieved August 25, 2020, from https://www.designcouncil.org.uk/sites/default/files/asset/document/Double Diamond Model 2019.pdf

Fernandes, S. da C. et al. (2020) 'Towards product-service system oriented to circular economy: A systematic review of value proposition design approaches', Journal of Cleaner Production, 257, p. 120507. https://dx.doi.org/10.1016/j.jclepro.2020.120507.

Gulden, T., Moestue, C., \& Berg, A. (2010). Psychology based design approach (PSYDA) - A pedagogical concept. In DS 62: Proceedings of E and PDE 2010, the 12th International Conference on Engineering and Product Design Education - When Design Education and Design Research Meet (pp. 376-381).

Kjaer, L. L. et al. (2019) 'Product/Service-Systems for a Circular Economy: The Route to Decoupling Economic Growth from Resource Consumption?', Journal of Industrial Ecology, 23(1), pp. 22-35. https://dx.doi.org/10.1111/jiec.12747.

Lidman, K., \& Renström, S. (2011). Design strategies in DfSB. Retrieved August 25, 2020, from https://sustainabilityguide.eu/methods/design-sustainable-behaviour/

Liedtke, C., Baedeker, C., Hasselkuß, M., Rohn, H., \& Grinewitschus, V. (2015). User-integrated innovation in Sustainable LivingLabs: An experimental infrastructure for researching and developing sustainable product service systems. Journal of Cleaner Production, 97, 106-116. https://doi.org/10.1016/j.jclepro.2014.04.070

Lilley, D. (2009). Design for sustainable behaviour: strategies and perceptions. Design Studies, 30(6), 704-720. https://doi.org/10.1016/j.destud.2009.05.001

Lindholdt, D. V. (2019). Tyske myndigheder slår fast: El-løbehjul er slet ikke så grønne endda. Retrieved August 13, 2020, from https://www.berlingske.dk/virksomheder/tyske-myndigheder-slaar-fast-el-loebehjul-er-sletikke-saa-groenne

Lockton, D., Harrison, D., \& Stanton, N. A. (2009). The Design with Intent Method: A design tool for influencing user behaviour. Applied Ergonomics, 41, 382-392. https://doi.org/10.1016/j.apergo.2009.09.001

Manzini, E., \& Vezzoli, C. A. (2002). Product-service systems and sustainability: Opportunities for sustainable solutions. UNEP-United Nations Environment Programme.

McAloone, T. C. and Bey, N. (2009) Environmental improvement through product development: A guide. Danish Environmental Protection Agency. Available at: http://www.kp.mek.dtu.dk/English/Research/areas/ecodesign/guide.aspx BT - Environmental improvement through product development.

Mont, O. (2004) 'Institutionalisation of sustainable consumption patterns based on shared use', Ecological Economics, 50(1-2), pp. 135-153. https://dx.doi.org/10.1016/j.ecolecon.2004.03.030.

Pialot, O., Millet, D., \& Bisiaux, J. (2017). "Upgradable PSS": Clarifying a new concept of sustainable consumption/production based on upgradablility. Journal of Cleaner Production, 141, 538-550. https://doi.org/10.1016/j.jclepro.2016.08.161

Pigosso, D. and McAloone, T. (2015) 'Supporting the Development of Environmentally Sustainable PSS by Means of the Ecodesign Maturity Model', Procedia CIRP, 30, pp. 173-178. https://dx.doi.org/10.1016/j.procir.2015.02.091.

Rozenfeld, H. et al. (2019) Servitization methodology: PSS design, change management or business model innovation?

Santamaria, L., Escobar-Tello, C., \& Ross, T. (2016). Switch the channel: Using cultural codes for designing and positioning sustainable products and services for mainstream audiences. Journal of Cleaner Production, 123, 16-27. https://doi.org/10.1016/j.jclepro.2015.09.130

Selvefors, A., \& Renström, S. (2018). Design for Sustainable Behaviour. Retrieved August 24, 2020, from https://sustainabilityguide.eu/methods/design-sustainable-behaviour/

Shih, L. H., Huarng, F., \& Jheng, Y.-C. (2017). Selecting persuasive strategies for design for energy-saving behavior. In Proceedings of the 2017 IEEE International Conference on Applied System Innovation: Applied System Innovation for Modern Technology, ICASI 2017 (pp. 1213-1216). https://doi.org/10.1109/ICASI.2017.7988108

Sumter, D., Bakker, C., \& Balkenende, R. (2018). The role of product design in creating circular business models: A case study on the lease and refurbishment of baby strollers. Sustainability (Switzerland), 10(7). https://doi.org/10.3390/su10072415

Tromp, N., Hekkert, P., \& Verbeek, P.-P. (2011). Design for Socially Responsible Behavior: A Classification of Influence Based on Intended User Experience. Design Issues, 27(3), 3-19. https://doi.org/10.1162/DESI_a_00087

Wever, R., van Kuijk, J., \& Boks, C. (2008). User-centred design for sustainable behaviour. International Journal of Sustainable Engineering, 1(1), 9-20. https://doi.org/10.1080/19397030802166205

Zachrisson, J., \& Boks, C. (2010). When to apply different design for sustainable behaviour strategies? In Knowledge Collaboration \& Learning for Sustainable Innovation ERSCP-EMSU conference, Delft. Retrieved from http://citeseerx.ist.psu.edu/viewdoc/download?doi=10.1.1.1032.492\&rep=rep1\&type=pdf 